\title{
How should a national curriculum for History be quality assured? \\ The case of the South African Curriculum and Assessment Policy Statement (CAPS)
}

\author{
Rob Siebörger \\ School of Education, University of Cape Town, Cape Town, South Africa \\ Orcid: 0000-0003-1016-4511 \\ Rob.Sieborger@uct.ac.za \\ DOI: http://dx.doi.org/10.17159/2223-0386/2021/n26a7
}

\begin{abstract}
The South African Council for Quality Assurance in General and Further Education and Training, known as Umalusi, embarked on a project to quality assure the South African Curriculum and Assessment Policy Statement (CAPS) curriculum for schools (2011) in 2012. This article analysis the process in terms of the history curriculum and provides a commentary on universal principles for the quality assurance of national curricula in general. Six quality assurance measures are identified and discussed: comparison between the outgoing and the incoming curricula; entry- and exit-level requirements; internal comparison between Phases [Key Stages] of the curriculum; comparison of the history curriculum statement with statements for other curriculum subjects; current trends in history education; and comparison with history curricula in other countries. Conclusions are drawn for Umalusi and its practice, the CAPS curriculum itself, and the history curriculum.
\end{abstract}

Keywords: Curriculum; Quality assurance; Accreditation; Umalusi; CAPS; NCS; Intermediate phase; Senior phase; FET; historical knowledge; historical skills. 


\section{Introduction}

This study is a retrospective analysis and evaluation of the quality assurance processes followed for the present South African national curriculum for History (Grades 4 to 12; approximate ages 9 to 17). It offers an insight into the issues involved when quality assuring a national curriculum for history ${ }^{1}$ and suggests potential lessons for future practice.

\section{Background}

The South African Qualification Authority (SAQA) was instituted in 1995. Amongst other responsibilities, it was entrusted with "registering national qualifications and standards; ensuring compliance with provisions for accreditation; [and] benchmarking standards and registered qualifications internationally" (SAQA Act, 58 of 1995). In 2008 these responsibilities were devolved to three Quality Councils: Umalusi - the Council for Quality Assurance in General and Further Education and Training, including schools; the Council on Higher Education (CHE) and Quality Council for Trades and Occupations (National Qualifications Framework Act, 67 of 2008).

In 2011 the South African Department of Basic Education (DBE) promulgated a new national curriculum, known as the Curriculum and Assessment Policy Statement (CAPS), ${ }^{2}$ to replace the previous curriculum, the National Curriculum Statements (NCS) of 2002 and 2003. ${ }^{3}$ The DBE had previously insisted that it had statutory responsibility for the school curriculum and did not, therefore, require additional accreditation from an outside body. In this instance, however, it requested Umalusi to "quality assure" the CAPS curriculum for all four phases of schooling. ${ }^{4}$

In the event, Umalusi decided that they should tackle the Further Education and Training (FET) phase (Grades 10-12) first, as the final year examinations (for the National

1 Quality assurance of a national curriculum for schooling as a whole or of a specific subject(s) conducted by a quality assurance authority appears to be very rare. I have been unable to find any instances of it other than this one. My belief is that it is a valuable process. This article seeks to draw attention to its benefits and pitfalls.

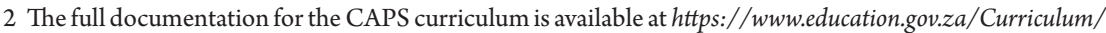
CurriculumAssessmentPolicyStatements(CAPS).aspx. Accessed on 14 November 2021.

3 The full documentation for the NCS curriculum is found at: https://www.schoolnet.org.za/teach $10 / c d / 10 /$ index.htm. Accessed on 14 November 2021. Note that the curriculum was initially published as the Revised NCS for Grades R-9 in 2002 and the NCS for Grades 10-12 in 2003.

4 Umalusi (2014a:12). Phase = Key Stage. Foundation Phase (Grades 1-3); Intermediate Phase (Grades 4-6); Senior Phase (Grades 7-9); Further Education and Training (Grades 10-12). 
Senior Certificate (NSC)) were to be written on the CAPS curriculum in 2014 (Umalusi, 2014a:14,18; Umalusi, 2014b:8). It created a template and set of criteria for undertaking a comparative study of the NCS and the CAPS ${ }^{5}$, which was used to analyse 13 FET subjects in 2013. Subject specialist teams employed by Umalusi, each consisting of six members, drawn from schoolteachers, provincial subject advisors and subject coordinators, universities, and curriculum developers, undertook the work (Umalusi, 2014a:22). Umalusi published an overview report and nine individual subject reports ${ }^{6}$ in 2014.

The study of the Intermediate Phase (IP; Grades 4-6) curriculum (Umalusi, 2013b) was conducted using the same template in 2013 and the third study, the Senior Phase (SP; Grades 7-9), followed in 2015 (Umalusi, 2015), also employing a similar template. Although it was intended to publish these two studies in the same manner as the FET study (Umalusi, 2014a:12), this was not done, and they remain unpublished.

The Umalusi comparative study provides a convenient means of highlighting principles of the quality assurance of a national curriculum. The examples to hand are the South African CAPS curriculum and the school subject history, but the curriculum principles are universal. Six quality assurance measures are identified and discussed. ${ }^{7}$

\section{Comparison between the outgoing and the incoming curricula}

Umalusi must have regarded this measure as especially significant to its project, as it titled its study A Comparative Study of the National Curriculum Statement and the Curriculum and Assessment Policy Statement. One might wonder whether there was any meaning attached to the calling it NCS and CAPS, instead of CAPS and NCS, when presumably the intention was to devote more attention to the new, and as yet untested, curriculum rather than the old.

5 The Umalusi authors of the template are not identified per se. Celia Booyse, Manager: Curriculum, conceptualised the project, which she co-managed with Sharon Grussendorff (Umalusi, 2014a:03). The same template, suitably adjusted, was used for each of the three phases.

6 The reports are available at https://www.umalusi.org.za/documents/reports/\#1558861281476-f372550b$8 d 6 f$. Accessed on 28 September 2021. Geography and history are combined into one report as social sciences (Umalusi, 2014b); accounting, business studies and management as business, commerce and management; life sciences and physical sciences as natural sciences.

7 Five of the six measures were employed in some manner in the Umalusi study, which included more detailed criteria derived from them. They have, however, been amended and expanded here. Measure 5, Current trends in history education, is included in the analysis in order to highlight its complete absence in the Umalusi study. 
The idea was clear that such a comparison would allow both the authorities and the public, in general, to be able to conclude whether, and in what ways, the new curriculum might be better or worse than the old. Considerable disquiet about some aspects of the NCS curriculum pressurised the Department of Basic Education ${ }^{8}$ to make improvements. It may be assumed that Umalusi was desirous of indicating to what extent they had done this. ${ }^{9}$ There had, however, been significant restrictions placed upon the writing teams for the CAPS curricula, including to "(r)emember that you are not starting from scratch. You are rewriting the content as it appears in the National Curriculum Statement to make it clearer, to ensure coherence from one grade to the next and one phase to the next, and to fill in content gaps where they exist." And that "A starting point would be to look at the current documents and to capture everything that is there" (Dada et al., 2010:11). The CAPS was, therefore, not a new curriculum but a revised curriculum.

However laudable the comparison between the old and new curriculum might have been in theory, there was a limit to what a paper-based, pre-textbook curriculum analysis could reveal, even with experienced and carefully selected evaluators. The issues chosen by Umalusi to include in this aspect of the study were: curriculum objectives, contents and skill coverage; breadth and depth; design, coherence, and structure; and pacing, sequencing, and progression. Each is discussed below.

\section{Curriculum objectives}

It was helpful for the Umalusi subject teams to compare the CAPS objectives with the previous NCS objectives. Predictably, they found no fundamental differences in the objectives regarding the purposes of teaching and learning history. Still, the analysis did reveal what might otherwise have been hidden: that CAPS underplayed aspects such as human rights, human agency, heritage, and democracy (Umalusi, 2014b:74-75).

\section{Content and skill coverage: breadth and depth}

The knowledge structure of history as a subject (Siebörger, 2019) does not lend itself to the comparison of content, whether in breadth or depth as the study also concluded: "It

8 See the Report of the Task Team for the Review of the Implementation of the National Curriculum Statement (Dada et al., 2009).

9 Hence the title of its 2014 published reports: What's in the CAPS package? 
is thus not possible to indicate which content is 'left out' in any grades as such a list would be almost infinite...," and, "It is not possible to make judgements about the depth in which topics should be covered according to the NCS, as the amount of time that teachers should spend on each topic is not given in the curriculum document, and the level of specification of the topics is not very detailed" (Umalusi, 2014b:75, 80). It was possible to comment on the breadth of content relative to the teaching time available in a year, particularly in the CAPS, which indicates the anticipated teaching hours per topic. As topics in the CAPS were specified in far more detail than in the NCS, it was much easier to interpret them and select relevant content knowledge (Umalusi, 2013b:24).

The Umalusi specialist team took the view that the CAPS content was well-selected overall and that "FET learners will develop a good overview of the key events in the world over the past 400 years" (Umalusi, 2014b:85). It expressed reservation about certain aspects of the historical content but concluded that "It is difficult to balance the breadth of coverage of world history, African history, and national history, together with sufficient depth to achieve understanding. The CAPS manages the tensions between breadth and depth as well as is possible, although there is probably still a greater emphasis on breadth than depth. Overall, the assessment of the team was there are no major omissions of content topics" (Umalusi, 2014b:86-87). These conclusions were necessarily subjective, and another teams might well have differed substantially from them. However, the Umalusi templates and processes demonstrated that it was possible to have an informed discussion on the choice of content of a curriculum under quality assurance review.

Regarding the "skills coverage" criterion, an attempt was made to identify which skills appeared to be present in each curriculum. However, it did not show much, other than that most skills were present in both curricula. A general conclusion was that the specification and coverage of skills were very similar in the two curricula but were approached differently. In the NCS, teachers chose to teach skills according to their choice of Learning Outcomes and Assessment Standards. In the CAPS, however, there was a table of skills. An accompanying observation on the CAPS was a quotation from it to the effect that "memory skills remain important” (DBE, 2011c:11; Umalusi, 2013b:29).

\section{Design, coherence, and structure}

One of the purposes of the Umalusi study was undoubtedly to demonstrate how the CAPS curriculum had departed from outcomes-based education (OBE) as a design principle, as per a Ministerial Project Committee instruction (Dada et al., 2009:49; Ministerial Project 
Committee, 2013). There was no similarity at all. In CAPS the curriculum was designed around the topics, while the NCS was designed around the Learning Outcomes (Umalusi, 2013b:42). Pursuing coherence as a profitable means to compare the two curricula in the Intermediate Phase was regarded as equally fruitless. It was found that in history there was no single central idea or overarching principle that could be employed to create coherence. Both the NCS and CAPS IP curricula had only attempted to do so in their use of the same four main ideas: more South African than world history; restricting South African history to pre-1600 (i.e., long ago); studies in development over time using universal themes; and relevance to the interests and needs of learners (Umalusi, 2013b:54).

\section{Pacing, sequencing, and progression}

The Umalusi FET study paid specific attention to these aspects. They defined pacing as "the relationship between the volume of learning material (topics to be covered) and the particular timeframe given to the subject". Sequencing was "the order in which topics are taught" and Progression was "the increase in the level of complexity or difficulty at which a topic is addressed through a grade or across the phase ${ }^{10}$ " (Umalusi, 2014a:31,32,33). In each of the three phases, the information sought from the specialist teams' comparison of the NCS and the CAPS, involved establishing to which extent each curriculum specified the involved aspects in enough detail and, thereafter, whether any conclusions could be drawn from the data gathered.

The general finding was that as the CAPS was specified in more detail than the NCS, one could find better evidence for all three of these aspects in the CAPS than the NCS. Arguably, the most effective device for pacing in the IP and SP CAPS was that there was one topic per term, which prompted teachers not to extend their teaching to the following term, or shorten it unnecessarily (Umalusi, 2015:20). To draw more meaningful conclusions, one would need detailed study examples from the curricula, rather than simply tallying instances of "High, Moderate, or Low" occurrences, which is what the Umalusi research template required. There is some evidence of examples being used in the final, Senior Phase study due to learning from the rather unfruitful results of the FET and Intermediate Phase studies in this regard.

10 While this definition is possibly appropriate for a national curriculum, it stresses the structural element of progression only, not the learning involved. Watts and Grosvenor (1996:24-25) define progression in history as learners' progress, "from where they are at a given point to what it may be hoped they can do at another." 
Concerning pacing, the Intermediate Phase study commented that it was influenced mainly by the teacher and the learners' interests and available resources. However, it was difficult to judge whether the pacing of the curriculum was too fast, too slow, or appropriate for the level of the development for learners in the different grades in the NCS, because that curriculum relied entirely on the ability of the teacher to achieve appropriate pacing (Umalusi, 2014b:32).

Apart from chronology and long-established curriculum tradition, the studies found little basis for sequencing content knowledge in history (Umalusi, 2014b:90). Content topics in both the NCS and the CAPS were self-standing units, which did not reveal different levels of complexity and could be taught in any sequence without consequences (Umalusi, 2015:33).

The FET study approached its comments on progression by noting that, "It is difficult in History to assess the complexity and difficulty of content topics, as this depends entirely on the depth of engagement. A topic like the French Revolution, for example, might be taught by just focusing on the causes and the events, which is not difficult for learners to understand. Alternatively, it may be taught with a stronger focus on the abstract philosophical ideas which underpinned the Revolution, which would be more conceptually demanding" (Umalusi, 2014b:91). For the Senior Phase, it was considered that there was some increase in content complexity and application in both curricula. Skills progression was marked in the NCS by the Assessment Standards, but it was scarcely present in the CAPS (Umalusi, 2015:33). The Intermediate Phase study baldly stated that there was no content/topic progression in either history curriculum. In history, progression was indicated in skills and concepts only (Umalusi, 2013b:40).

\section{Entry- and exit-level requirements}

At first, comparing the curriculum documents against acknowledged entry- and exit-level requirements for the phases represents an essential and valuable means of quality assuring the curriculum. There is universally much to commend it. However, in South Africa, it only applies tangentially in subjects such as history (though it may have greater relevance in mathematics and the sciences).

The obvious exit-level requirements for the curricula are those set for the Grade 12 school-leaving National Senior Certificate examinations. Here, the CAPS history improved considerably on the NCS by including the examination requirements in the curriculum document, together with exemplars (DBE, 2011a:39-50), thus making the link between 
the curriculum and the examination evident. There was previously no direct link between the NCS and the NSC. But, most curiously, Umalusi, the certifying body for the NSC, did not examine these exit-level requirements in its FET study ${ }^{11}$.

The Umalusi IP and SP studies did, in contrast, attempt to analyse the exit level of each phase - what the outcomes were for Grade 6 and Grade 9, respectively. In each instance, the specialist teams responded by examining the table of eight Specific aims and skills of History CAPS for the Intermediate and Senior Phases (DBE, 2011c:11). They concluded that it was possible to develop higher-order thinking and higher-order skills in history in the Intermediate Phase. This required a thorough grounding in the lower order skills as a basis, a structured progression in both aims and skills [the exit level outcomes], and how the content was specified (Umalusi, 2013b:132). Unfortunately, it is far from measuring to what degree the curricula matched a set of exit-level standards. However, it does indicate that it would be possible to construct and validate a history curriculum according to set entry and exit levels per phase.

\section{Internal comparison between Phases [Key Stages] of the curriculum}

As the CAPS curriculum was envisaged as a single curriculum from Grades R[ecption]-12 (Dada et al., 2010:62) (2) $^{12}$ the internal consistency between phases is important. An analysis of how this operates contributes to the quality assurance of the curriculum as a whole. The Umalusi study was not designed to enable such a comparison. The fact that the instruments used to investigate each phase were similar in many ways and that membership of the three Umalusi specialist teams overlapped to some extent between phases, makes it possible to comment on internal comparison between them.

The three Umalusi specialist teams' reporting in the phase studies on the CAPS is similar, indicating a substantial measure of internal consistency. Two examples illustrate this. The first is the "specification of topics, ${ }^{13}$ " which required a choice of "High, Medium or Low" specification and a justification for the option chosen. In all three instances, the decision was that the CAPS had a high degree of specification. The justifications provided

11 The only reason for this that comes to mind is that not all the CAPS subjects included the NSC examination requirements in their curriculum. Geography, for instance, did not (DBE 2011b) and they are sourced separately.

12 There were, however, three separate teams of curriculum writers for the CAPS Foundation Phase, Intermediate and Senior Phases and the Further Education and Training Phase, who did not work together, though they exchanged information,

13 For the IP: Umalusi, 2013b:28-29; for the SP: Umalusi, 2015:16-17; for the FET: Umalusi, 2014b:82-83. 
by the teams corresponded, referring in each instance to the numbers of bullet points and their use in the CAPS' content descriptions.

The second is "curriculum coherence. ${ }^{14 "}$ The three studies agreed that the curriculum coherence was based on a chronological approach and that it was stronger in the CAPS than the NCS. The logic of each, though, was expressed somewhat differently. Except for chronology, there was no single central idea or overarching principle to create coherence in history for the IP. For the SP, the coherence of both the NCS and the CAPS was developed through chronological sequencing. However, the CAPS both strengthened and weakened coherence, as the skills were more plainly expressed and explained but were not linked directly to the content knowledge. For the FET, the CAPS employed a broad chronology of events from the seventeenth century to the present. Both CAPS and the NCS made connections between topics, but they were more explicit in the CAPS.

\section{Comparison of the history curriculum statement with statements for other curriculum subjects}

To what extent should there be external coherence between the curricula for all CAPS subjects, beyond the broad general requirements set at the time for all the curriculum writing teams? This question has been key in constructing South African curricula since the late 1990s. With Curriculum 2005 in 1996-1998, the answer was that there ought to be a large amount of collaboration and cross-checking between Learning Area Committee writing teams. With the NCS, there was less collaboration, but the writing groups all met at the same time and place and compared notes daily. With the CAPS, there was no collaboration at all between the different subject curriculum writers. ${ }^{15}$ One may ask whether the quality assurance of the CAPS subject curricula would not have been more thorough had it included more comparison with other subjects. Although there was some accidental comparison when history and geography subject specialists worked together in a "Social Sciences" team, which merely confirmed that had Umalusi included it in their research template, they could have directly compared the subjects.

However, the Umalusi project managers took the opportunity to compare aspects of the findings of the FET subject specialist teams when they compiled the Overview Report at the end of the study. These are their main observations:

14 For the IP: Umalusi, 2013b 41-42; for the SP: Umalusi, 2015: 31; for the FET: Umalusi, 2014b:96.

15 Personal involvement. 
- Regarding the design principle of the CAPS

All... agreed that the design principle of the CAPS has shifted from outcomes-based in the NCS to being content-driven or syllabus-based (Umalusi, 2014a: 45).

- Regarding curriculum objectives

The general finding across the subjects was that the objectives are very similar for both curricula. And, "[t]aken together, these observations suggest a profound shift in the curriculum, which has become a technical instruction with academic performance as the single most important indicator of educational achievement (Umalusi, 2014a: 45).

- Regarding the breadth of curriculum coverage

The Economics and Mathematics evaluation teams reported an increase in the breadth of content across the FET Phase in the move from the NCS to the CAPS.... English HL, Accounting, Business Studies, and History evaluation teams concluded that the breadth across the FET Phase is similar for the NCS and the CAPS... The Physical Sciences, Life Sciences, Geography, and English FAL evaluation teams reported a reduction in the breadth of content across the FET Phase in the CAPS compared with that in the NCS (Umalusi, 2014a: 46).

\section{- Regarding depth}

An increase in depth from the NCS to the CAPS was noted for Economics and Mathematics... The Accounting, Business Studies, Geography, and Physical Sciences evaluation teams reported similarity in depth required across the FET Phase for the NCS and the CAPS... The English FAL and Life Sciences evaluation teams reported a reduction in overall depth... The History evaluation team could not compare the depth of the curricula because the structure of the content outline provided in the NCS does not give sufficient detail... (Umalusi, 2014a: 48-49).

- Regarding specification of content

On the whole, it was found that the level of specification of content is higher in the CAPS than in the NCS. More detail is provided on the exact scope and depth of the content that is to be taught and assessed. However, three of the evaluation teams, namely Economics, English HL and English FAL, did not report an increase in specification of content in the CAPS” (Umalusi, 2014a: 50).

- Regarding pacing

For the CAPS, all of the subjects except for Geography, Mathematical Literacy, and Life Sciences made the comment that pacing is likely to be experienced as fast by the learners... (Umalusi, 2014a: 52). 


\section{- Regarding sequencing and progression}

For the CAPS, no clear trend is evident across the subjects in terms of the sequence of topics allowing for progression within each grade... all of the subjects, with the exception of the language evaluation teams, reported a clear progression across the grades" (Umalusi, 2014a: 53).

\section{Current trends in history education}

The only reference to current literature in history education in any of the Umalusi research studies was a quote by Jamie Byrom (2014) used to support an argument regarding exitlevel outcomes in the SP CAPS (Umalusi, 2015:52). It read, in part,

Getting better at history requires all aspects of the discipline to be developed together. We may be able to set out separate summaries of the "historical knowledge" and "historical skills and concepts" in describing a course but they need to be carefully blended in all planning and teaching... Only when both aspects of history are carefully and thoroughly mixed in the appropriate balance is the subject discipline really being developed. It is as foolish to say that "It is the skills that matter" as it is to say that "It is the knowledge that matters."

By its authority and clarity, this quotation eloquently illustrates the necessity for conducting a survey of current literature in history education to do curriculum evaluation and quality assurance in an informed manner. The absence of such a survey was a very significant gap in the Umalusi approach to quality assurance.

\section{Comparison with history curricula in other countries}

It is an open question whether comparisons with the national history curricula of other countries can assist an accreditation process. But, such comparisons will inevitably contribute useful insights into quality assurance, if through nothing else, by focusing on conspicuous omissions. It was a fairly bold move by Umalusi ${ }^{16}$ to attempt such "benchmarking" (their term) when so many subject curricula were involved, and it met

16. Umalusi had, however, had some prior experience of such comparisons. See Umalusi, 2008 and Umalusi, 2010. 
with mixed results ${ }^{17}$. The curricula of three English-speaking Commonwealth countries British Columbia, Kenya, and Singapore, were selected for the exercise. ${ }^{18}$ The investigation adopted the template of the NCS-CAPS comparison and comprised in the main a set of tables to be completed, specifying either numerical analysis, percentages, or High/ Medium/Low prevalence estimations, together with a textual comment to elaborate on the results.

As may be seen from the following summary conclusions, there was much of interest to be gleaned from the task, yet not a great deal that one could immediately apply to the CAPS. The Intermediate and Senior Phase studies (Umalusi, 2013b:159-161, and Umalusi, 2015:78-79) determined:

CAPS is very explicit in the instructions about content to be covered. All the topics are specified in detail and provide assessment and revision sections that assume that the content has been covered in the described manner. The implied role of the teacher in the CAPS suggests that teachers are primarily transmitters of a structured and rigid curriculum and facilitators of enquiry. Much of the responsibility for planning learning programmes is taken away from them. The evaluation team notes the absence of guidance on how to integrate skills and content. The level of content specification could reduce the scope for creativity in teaching, but this specification also guides less experienced teachers.

The British Columbian curriculum follows an enquiry-based approach with a high degree of specification. Detailed guidance is given on how to follow an enquiry approach. The curriculum document provides clear prescribed learning outcomes, how these are to be achieved by learners, and how teachers can enable this learning. It is reinforced through the explicit attempt to link enquiry skills and content. Five curricula organisers are used to group a set of prescribed learning outcomes that share a common focus. These learning outcomes and achievement indicators are intended to provide a framework for the curriculum to support the skills and processes essential to social studies and to specify content.

The Social Studies syllabus in Kenya specifies content topics in detail, and specific objectives under each topic guide them. It follows a fact-based approach to the teaching

17 This might explain why the published FET report, (Umalusi, 2014b), excludes this aspect of the research. 18. It is likely but unverified that Umalusi used the same three countries for all the subject curricula included in the studies. 
and learning of history, with a clear link to Kenyan realities. The level of specification is low, as there is no explicit indication of a pedagogical approach. However, direct [teachercentred] instruction can be implied from the verbs in the specific objectives provided for each topic.

In the Singaporean curriculum, an inquiry focus question anchors the study of a topic. At the same time, the key understandings reflect the main insights that pupils would gain through the study. These are further guided by knowledge, skills and values outcomes, and key concepts. There is an enquiry-based approach linking content to the real world. This association is more evident in the upper secondary combined humanities curriculum. A high level of specification is provided, which indicates what an enquiring student can and cannot do. Clear links are made between knowledge, skills, and concepts to be taught and practised.

\section{Concluding commentary}

The research studies undertaken by Umalusi demonstrated for the first time the role that a quality assurance body could play in the evaluation and quality assurance process for a national curriculum for schooling in South Africa and perhaps in the world. They were thorough and substantial enough to give any doubters reason to re-consider and appreciate what an independent quality assurance body could contribute to a state-sponsored national curriculum project. Suppose the studies had taken place when they should ideally have done, between the final draft submission and the publication of the curriculum, before any textbooks were written, there is no doubt that they would have resulted in a significantly improved curriculum. From a research and development point of view, there is much that Umalusi can learn about its processes and research templates to tool itself for the next round of curriculum renewal in the country. ${ }^{19}$

There is also much that this work can inform one about the CAPS. Most prominently, the CAPS improved on the NCS in important facets. With relatively few exceptions, it delivered what the Department of Basic Education and its Ministerial Project Committee desired. A comparison of the studies revealed what was lost by adopting the CAPS curriculum, and in some instances, what one might do to put this right. The focus on the

19 This might happen sooner for history than other school subjects, depending on how the proposals-in-the-making of the Ministerial Task Team for History are acted upon by the Department of Basic Education. 
aspects such as pacing, sequencing, and progression is both novel and crucial for a South African national curriculum.

For history as a subject, there are also essential takeaways. The investigations showed how relatively arbitrary the content knowledge in the three CAPS curricula is. Its choice required far more justification than is provided in the NCS and CAPS ${ }^{20}$. They further highlighted the fact (see Byrom above) that historical skills and concepts had to be developed together with historical knowledge. The CAPS had failed to bring them into proper conjunction. The studies showed very clearly that the discipline of history is the key to evaluating a curriculum for schools, as it determines how one analyses the intended results. Thus, the need for thorough literature surveys in history education to accompany any evaluations. They also revealed that for meaningful comparison and benchmarking, 'like' must be compared with 'like'. There was little point in some of the comparisons made between the NCS history and the CAPS history when there was no common basis for them. Neither was there very much to be gained by comparing social studies curricula in British Columbia and Singapore with a history curriculum in South Africa. A final observation is that when one compares the history curriculum with the curricula for other subjects, it is essential to pay careful attention to the knowledge structure of each of the subjects involved in the comparison.

20 As has been highlighted by the work of the Ministerial Task Team for history (DBE, 2018) and, for example, by the present debates around powerful knowledge in history, see Chapman, 2021. 


\section{References}

Byrom, J. 2014. Progression in history under the 2014 National Curriculum. A guide for schools. London: Historical Association. Available at https://www.exeter.ac.uk/media/ universityofexeter/collegeofsocialsciencesandinternationalstudies/education/pgce/ pre-coursedocuments/pre-coursedocuments2018-19/Progression_in_History_ under_the_2014_National_Curriculum.pdf. Accessed on 14 November 2021.

Chapman, A. (ed.) 2021. Knowing history in schools: powerful knowledge and the powers of knowledge. London: University College.

Dada, F. et al. 2009. Report of the task team for the review of the implementation of the National Curriculum Statement. Final report. Pretoria: Department of Basic Education.

DBE 2011a. Curriculum and Assessment Policy Statement Grades 10-12 History. Pretoria: Department of Basic Education.

DBE 2011b. Curriculum and Assessment Policy Statement Grades 10-12 Geography. Pretoria: Department of Basic Education.

DBE 2011 c. Curriculum and Assessment Policy Statement Grades 4-6 Social Sciences. Pretoria: Department of Basic Education.

DBE 2018. Report of the history ministerial task team for the Department of Basic Education. Pretoria: Department of Basic Education. Available at https://www.education.gov.za/ Portals/0/Documents/Reports/Report\%20of\%20the\%20History\%20Ministerial\%20 Task\%20Team.pdf?ver=2018-06-07-154241-410. Accessed on 14 November 2021.

Ministerial Project Committee 2013. Briefing for CAPS curriculum writers. Unpublished document.

Siebörger, R. 2019. Knowledge structures and school history. Public History Weekly. Available at https://public-history-weekly.degruyter.com/7-2019-13/knowledgestructures/. Accessed on 14 November 2021.

Umalusi, 2008. Learning from Africa-Science: Umalusi's research comparing syllabuses and examinations in South Africa with those in Ghana, Kenya, and Zambia. Pretoria: Umalusi.

Umalusi, 2010. Comparing the learning bases: An evaluation of Foundation Phase curricula in South Africa, Canada (British Columbia), Singapore, and Kenya. Pretoria: Umalusi.

Umalusi 2013a. Background information for curriculum comparison project. Pretoria: Umalusi. Umalusi 2013b. Curriculum evaluation: intermediate phase. A comparative analysis of 
the National Curriculum Statement (NCS) and the Curriculum and Assessment Policy Statement (CAPS) and with respective international qualifications. (Working document). Pretoria: Umalusi.

Umalusi 2014a. What's in the CAPS package? A comparative study of the National Curriculum Statement (NCS) and the Curriculum and Assessment Policy Statement (CAPS). Further education and training phase. Overview report. Pretoria: Umalusi. Available at https:// www.umalusi.org.za/docs/reports/2014/overview_comparitive_analysis.pdf Accessed on 14 November 2021.

Umalusi 2014b. What's the CAPS package? A comparative study of the National Curriculum Statement (NCS) and the Curriculum and Assessment Policy Statement (CAPS). Further education and training phase. Social sciences [geography and history]. Pretoria: Umalusi. Available at https://www.umalusi.org.za/docs/reports/2014/social_sciences.pdf . Accessed on 14 November 2021.

Umalusi 2015. Curriculum evaluation: senior phase. A comparative analysis of the National Curriculum Statement (NCS) and the Curriculum and Assessment Policy Statement (CAPS) and with respective international qualifications. (Working document). Pretoria: Umalusi. Watts, R \& Grosvenor, I. 1995. Progression in children's learning in history, in Crossing the Key Stages of History. Effective History Teaching 5-16 and Beyond. Watts, R and Grosvenor, I. (eds.). London: David Fulton. 